\title{
The Risk of Impaired Coagulation in Surgical Jaundice: An Analysis of Routine Parameters
}

\author{
David O. Irabor \\ Surgery Department, University College Hospital (UCH), Ibadan, Nigeria \\ Email: dirabor@comui.edu.ng
}

Received November 9, 2011; revised December 28, 2011; accepted January 11, 2012

\begin{abstract}
The study is a retrospective study of 30 patients who had operations for obstructive jaundice at the University College Hospital Ibadan, Nigeria between 1998 and 2003. The aim was to see if one could predict the patients at risk of bleeding by analysing the routine investigations like the Packed Cell Volume (PCV), Serum bilirubin levels, Alkaline phosphatase and the International Normalised Ratio (INR). These parameters were analysed against the age and pathology of the condition i.e. the respective diagnoses. The male/female ratio was 1:1.4 and the mean age was 52.8 years. The mean total bilirubin was $14.2 \mathrm{mg} \%$ (241.4 micromol/L) and the mean PCV was $31.6 \%$. The condition of the pathology was split between carcinoma of the head of pancreas, carcinoma of the gall bladder, common bile duct stone and peri-ampullary carcinoma. The results suggest that the risk of haemorrhage increases with age and the levels of bilirubin beyond $15 \mathrm{mg} \%$ (255 micromol/L) in persons with carcinoma of the gall bladder.
\end{abstract}

Keywords: Obstructive Jaundice; Bleeding; Correlation with Investigations

\section{Introduction}

Obstructive jaundice may be complicated by a bleeding diathesis which may have its origins from the lack of vitamin K-dependent clotting factors and ultimately as the result of hepatic decompensation and malfunction. $[1,2]$ Part of the management of patients with obstructive jaundice in our centre is the empirical administration of parenteral vitamin $\mathrm{K}$ and the precaution of making arrangements for fresh frozen plasma, fresh whole blood and cryoprecipitate [1]. There may exist some patients who are at greater risk of bleeding than others for reasons initially undetermined. In other words, there may be some patients who really do not need to have these precautions implemented because they are at no risk of bleeding. In a poverty-stricken environment like ours, unnecessary administration of medications leads to increase financial hardship on the patients. This study seeks to find out if there is any correlation between some observed demographic and investigation parameters and the likelihood of developing a bleeding complication. So that resources are properly channelled towards those patients that will really benefit from them.

\section{Methodology}

This is a retrospective study of 30 patients operated upon in the University College Hospital Ibadan with jaundice from extra-hepatic bile-duct obstruction between 1998 and 2003. Their ages, sex, presenting levels of serum bilirubin, alkaline phosphatase, packed cell volume and the International normalized ratios (INR) were recorded. The INR was devised to standardise the results of Prothrombin time ratios because of differences in the types of tissue factor manufactured by different companies. In essence there is an International Sensitivity Index (ISI) given by the manufacturer for any tissue factor produced. The ISI is usually between 1.0 and 1.4. The INR is thus the PT ratio raised to the power of the ISI used. If it is one the PT ratio will give the same value as the INR, however it is not synonymous with the INR. All the admitted patients had standard pre-operative preparation for obstructive jaundice viz. parenteral vitamin $\mathrm{K}$, bowel preparation, adequate hydration to ensure satisfactory urinary output, mannitol infusion at induction of anaesthesia and broad spectrum antibiotics. These patients were operated upon by three different sets of consultant general surgeons and all the operations were performed under general anaesthesia with endotracheal intubation. The aetiopathogenesis of the obstructive jaundice in these patients confirmed at operation were of four types: Common bile duct (CBD) stones, Carcinoma of the head of the pancreas (CaHOP), Carcinoma of the gall bladder (CaGB) and Peri-ampullary carcinoma (PACa). The patients with common bile duct stones had cholecystectomy, choledochotomy with stone extraction and t-tube insertion, those with carcinoma of the head of the pancreas 
had bypass surgery (cholecystojejunostomy or choledochojejunostomy with jejunojejunostomy and gastrojejunostomy) whilst not much could be done with the patients who had carcinoma of the gall bladder and periampullary carcinoma at exploratory laparotomy. The author wanted to match the investigation parameters at presentation with the respective INRs to see whether those who presented with deranged INRs correlated with a certain age, level of bilirubin or level of alkaline phosphatase.

\section{Results}

There were 30 patients, 14 male and 16 female.

Male: Female ratio 1: 1.4. Age range was 36 to 81 years.

The mean age was 52.8 years. There were 20 patients at the age of 50 and above $(66.7 \%)$.

Haematological test results (Table 1): Packed cell volume ranged from $18 \%-42 \%$ with a mean of $31.6 \%$.

INR ranged from $0.9-2.3$. Only six INR results (20\%) were above 1.5 . These were four patients with carcinoma of the head of the pancreas and two with carcinoma of the gall bladder.

Liver function test results (Table 1): Total bilirubin levels ranged from 7.1 - $24.2 \mathrm{mg} \%$ (120.7 - 411.4micromol/L) with a mean of $14.2 \mathrm{mg} \%$ (241.4micromol/L). Conjugated bilirubin levels ranged from 3.0 - $17.6 \mathrm{mg} \%$ (51 $299.2 \mathrm{micromol} / \mathrm{L})$ with a mean of $10.2 \mathrm{mg} \%(173.4 \mathrm{mi}-$ cromol/L). Alkaline phosphatase levels ranged from 200 - $2850 \mathrm{iu} / 1$ with a mean of $900 \mathrm{iu} / 1$.

Intra-operative diagnoses (Table 2): CaHOP occurred in 17 patients $(56.7 \%)$ made up of 10 male and seven female. Mean age 55.7 years.

CBD stones were present in 8 patients $(26.7 \%)$; two male and six female. Mean age 43.5 years.

$\mathrm{CaGB}$ was seen in 4 patients $(13.3 \%)$; two male and

Table 1. Summary of haematological and biochemical investigation.

\begin{tabular}{ccc}
\hline & Range & Mean \\
\hline Age & $36-81$ years & 52.8 years \\
HAEMATOLOGY & $18 \%-42 \%$ & $31.6 \%$ \\
PCV & $0.9-2.3$ & 1.3 \\
LIVER BIOCHEMISTRY & & \\
Total Bilirubin & $7.1-24.2 \mathrm{mg} \%$ & $14.2 \mathrm{mg} \%$ \\
Conjugated Bilirubin & $3-17.6 \mathrm{mg} \%$ & $10.2 \mathrm{mg} \%$ \\
Alkaline Phosphatase & $200-2850 \mathrm{in} / 1$ & $900 \mathrm{iu} / 1$ \\
\hline
\end{tabular}

Table 2. Pathological findings.

\begin{tabular}{ccccc}
\hline $\begin{array}{c}\text { Intra-operative } \\
\text { diagnosis }\end{array}$ & $\begin{array}{c}\text { Total number } \\
\text { of patients }\end{array}$ & Male & Female & $\begin{array}{c}\text { Mean age } \\
\text { (Years) }\end{array}$ \\
\hline $\begin{array}{c}\text { Carcinoma of Head } \\
\text { of Pancreas }\end{array}$ & 17 & 10 & 7 & 55.7 \\
$\begin{array}{c}\text { Common Bile } \\
\text { Duct Stones }\end{array}$ & 8 & 2 & 6 & 43.5 \\
$\quad \begin{array}{c}\text { Carcinoma of } \\
\text { The Gall Bladder }\end{array}$ & 4 & 2 & 2 & 62.5 \\
$\begin{array}{c}\text { Peri Ampullary } \\
\text { Carcinoma }\end{array}$ & 1 & 1 & 0 & 42 \\
\hline
\end{tabular}

two female. Mean age 62.5 years. PACa occurred in 1 patient $(3.3 \%)$; 1 male only, age 42 years.

\section{Discussion}

The risk of bleeding in patients with obstructive jaundice among other complications like hepatorenal syndrome, hepatic encephalopathy and sepsis may increase morbidity and mortality in these group of patients [1,2]. This discussion will confine itself to the observations made by the author on the apparent links or otherwise of the routine demographic and investigatory parameters obtained for patients with obstructive jaundice in most hospitals. Indeed a derangement in the clotting parameters routinely measured e.g. PT ratio and INR, are the indices we have to go by to "nip in the bud", so to speak, patients who are at risk of uncontrollable bleeding post-operatively. Many surgeons will consider an INR of 1.3 safe for surgery [3] since studies have shown that there is no increase in bleeding complications with an INR of 1.3. [4] This translates to a 4 - 5 second prolongation of the prothrombin time [4]. Bleeding complications in obstructive jaundice have been shown to have an additional cause from endotoxemia which may lead to low grade disseminated intravascular coagulation $[5,6]$. These endotoxins are thought to be derived from the gut [6] hence a proper bowel preparation goes a long way in minimising this potential problem. In weighing the significance of the INR value before surgery, one may wish to note that it has been observed that tests for PT in vitro may not necessarily translate to the state in vivo [7]. In hypoprothrombinemia, bleeding does not usually occur until the INR is about 2 [8].

While observing the mean values of these parameters a certain trend started to emerge when set against the INR range (Table 3); the tendency for a prolongation of the PT increased with an increase in the mean age and increase in the level of the mean conjugated bilirubin level. The alkaline phosphatase level did not correlate with the levels of any of the parameters. The explanation may lie in the observation that there may be two factions of alkaline phosphatase found in bile; one from the liver cell 
Table 3. The relation between INR and other parameters.

\begin{tabular}{|c|c|c|c|c|c|}
\hline INR & No of patients & $\%$ of total & Mean age (years) & Mean direct bilirubin (mg\%) & Mean alkaline phosphatase (iu/l) \\
\hline 0.9 & 2 & 6.7 & 49 & 8.4 & 1373 \\
\hline 1 - 1.1 & 8 & 26.6 & 49.4 & 9.3 & 1026 \\
\hline $1.2-1.3$ & 12 & 40 & 52.3 & 9.7 & 689 \\
\hline 1.4 & 2 & 6.7 & 55 & 13.5 & 1260 \\
\hline 1.5 and $>$ & 6 & 20 & 59.3 & 15 & 874 \\
\hline
\end{tabular}

Table 4. Relation of the pathology to measured parameters.

\begin{tabular}{ccccc}
\hline Diagnosis & Mean conjugated bilirubin (mg\%) & Mean INR & Mean PCV (\%) & Mean alkaline phosphatase (iu/l) \\
\hline CaHOP & 12.13 & 1.3 & 31 & 1085 \\
Calculi & 6.33 & 1.1 & 32 & 702 \\
CaGB & 10.48 & 1.5 & 29 & 625 \\
\hline
\end{tabular}

$\mathrm{CaHOP}=$ Carcinoma of the head of the pancreas; Calculi $=$ Common bile duct stones; $\mathrm{CaGB}=$ Carcinoma of the gall bladder.

Table 5. Correllation between INR and other parameters.

\begin{tabular}{ccc}
\hline Parameter & r & P \\
\hline Total bilirubin & 0.165 & 0.383 \\
Conjugated bilirubin & 0.300 & 0.107 \\
Alkaline phosphatase & -0.173 & 0.360 \\
\hline
\end{tabular}

$\mathrm{P}$ is significant if $\leq 0.05 ; \mathrm{r}$ is correlation coefficient.

and the other only appears when there is obstruction to the flow of bile [7]. Thus measurement of the total level may give varied values depending on the completeness or otherwise of the obstruction and/or the hepatocellular function [7]. A tendency to bleeding with increasing age may also point to the ageing process affecting the liver. The higher the level of conjugated bilirubin the greater the risk of bleeding because this translates into a longer period of obstruction with lack of formation of vitamin K-dependent clotting factors, back-pressure effects on the liver leading also to non-production of other clotting factors and increased time for gut-derived endotoxins to cause mild DIC. In this study the critical level of mean conjugated bilirubin at which a significantly deranged INR of 1.5 and above occurred was $15 \mathrm{mg} \%$ and a mean age of 59.3 years and above. When the mean levels of these parameters were set against the intra-operative diagnoses (Table 4), it showed that carcinoma of the head of the pancreas had the highest level of conjugated bilirubin and alkaline phosphatase though the INR was within surgical safety range whereas carcinoma of the gall bladder showed a tendency to derangement in clotting parameters even at lower conjugated bilirubin levels and lowest alkaline phosphatase levels. Gall stones showed the lowest INR and bilirubin levels. The calculated coef- ficient of correlation showed a small positive correlation between the total bilirubin and the INR, this became moderately stronger with the conjugated bilirubin and the INR whereas the alkaline phosphates showed no correlation with the INR (Table 5). However the P values for these were not significant; this may be due to the small study size of 30 patients, nevertheless, this study may well serve as a pilot while more patients are being studied.

In conclusion, these observations suggest that patients who are 60 years of age and above with conjugated bilirubin levels of more than $15 \mathrm{mg} \%$ and have carcinoma of the gall bladder may be at a greater risk of bleeding complications from obstructive jaundice.

\section{REFERENCES}

[1] D. C. Carter, J. M. S. Johnstone and I. B. Macleod, "The Gall Bladder, the Bile Ducts and the Pancreas," In: R. F. Rintoul, Ed., Farquharson's Textbook of Operative Surgery, 8th Edition, Churchill Livingstone, Edinburgh, 1998, pp. 421-449.

[2] A. Nakeeb, K. D. Lillemoe, C. J. Yeo and J. L. Cameron, "Neoplasms of the Exocrine Pancreas," In: L. J. Greenfield, Ed., Surgery, Scientific Principles and Practice, 3rd Edition, Lippincott Williams and Wilkins, Philadelphia, 2001, pp. 885-899.

[3] E. A. Badoe, E. Q. Archampong and M. O. A. Jaja, "Principles and Practice of Surgery," 2nd Edition, Liver and Biliary System, Ghana Publishing Corporation, Tema, 1994, pp. 657-688.

[4] S. S. Shapiro, J. Martinez, L. A. Harker, "Thrombosis and Haemostasis," In: J. R. McArthur and J. E. Menitove, Eds., Haematology, Copyright American Society of Haematology, Washington DC, 1992, pp. 51-59. 
[5] R. D. Hunt, M. E. M. Allison, C. R. M. Prentice and L. H. Blumgart, "Endotoxemia, Disturbance of Coagulation and Obstructive Jaundice," The American Journal of Surgery, Vol. 144, No. 3, 1982, pp. 325-329.

doi:10.1016/0002-9610(82)90011-3

[6] J. A. Pain, C. J. Cahill and M. E. Bailey, "Perioperative Complications in Obstructive Jaundice: Therapeutic Considerations," British Journal of Surgery, Vol. 72, No. 12,
1985, pp. 942-945. doi:10.1002/bjs.1800721203

[7] I. S. Benjamin, "Biliary Tract Obstruction-Pathophysiology," Blumgarts' Surgery of the Liver and Biliary Tract, Vol. 1, Churchill Livingstone, Philadelphia, 1990; pp. 111-117.

[8] R. B. Thompson, "A Short Textbook of Haematology," 5th Edition, Pitman Medical, London, 1979, pp. 419-453. 